\title{
Comments on the Article by L.V. Ksanfomality "Results of the New Processing of Images Obtained from the Surface of Venus in a TV Experiment Onboard the Venera-9 Lander (1975)"
}

\author{
O. L. Vaisberg \\ Institute of Space Research, Moscow, Russia \\ Received March 27, 2012
}

\begin{abstract}
The manuscript by L.V. Ksanfomality continues the theme published earlier in "Astronomicheskii Vestnik" (Ksanfomality, 2012). The article is of great epistemological interest. The existence of extraterrestrial life that is similar to ours, or strongly differs from it, is one of the most important problems of modern natural science. Where we came from, whether there is any more life in the Universe, whether it differs from ours are questions of interest to both researchers and many thinking people on the Earth. It is not without reason that the search for extraterrestrial life is a focus of the NASA space program.
\end{abstract}

DOI: $10.1134 / \mathrm{S} 0038094612050115$

Being a man of intellectual curiosity and inquisitive mind, Leonid Vasilyevich turned to the experimental material of the 1970s and 1980s: the Venus' surface panoramas obtained by the Soviet Venera landing vehicles (Selivanov et al., 1976; 1983). He advanced the supposition that this factual material could be used to search for signs of life on Venus as a model object of many moderately hot planets near other stars. He relied upon the supposition that life in the Universe must not necessarily be life of a terrestrial type, which is natural and popularly believed in this field.

The author carried out the additional processing and careful study of a series of the Venus' surface panoramas obtained by the Venera-9 landing vehicle. This resulted in his revealing several image fragments that moved on the Venusian surface, or had unusual morphological signs, whose accidental appearance is hard to combine with their morphological organization. I believe that the analysis performed by the author, and its thoroughness, show convincingly enough the reality of the appearance and dynamics of objects in the vision field of the Venera-9 landing vehicle. The interpretation of these objects as representatives of life on the Venusian surface seems to be rather logical, but, in my opinion, not proved absolutely. Being acquainted with the author's results (in addition to the phenomena expounded in the manuscript), I think it important to familiarize the scientific and broader audience with the results of the research.

I am persuaded that the problem under consideration is of exclusive importance and significance for subsequent research and has a educational value.

\section{REFERENCES}

Ksanfomality, L.V., Venus as a Natural Laboratory for Search of Life in High Temperature Conditions: Events on the Planet on March 1, 1982, Solar Syst. Res., 2012, vol. 46, no. 1, pp. 41-53.

Selivanov, A.S., Chemodanov, V.P., Naraeva, M.K., et al., TV Experiment on the Venus Surface, Kosm. Issl., 1976, vol. 14, no. 5, pp. 674-677.

Selivanov, A.S., Gektin, Yu.M., Gerasimov, M.A., et al., Continuation of the Venus Surface TV Research by Landing Probes, Kosm. Issl., 1983, vol. 21, no. 2, pp. $176-182$. 